\title{
Analysing Bidding Trends in Online Auctions
}

\author{
Rodel Balingit, Jarrod Trevathan and Wayne Read \\ Discipline of Information Technology \\ James Cook University, Australia \\ Email: rodel.balingit/jarrod.trevathan/wayne.read@jcu.edu.au
}

\begin{abstract}
Online auctions such as eBay are becoming increasingly more important mechanisms for people to buy and sell items online. In general, e-commerce is becoming fundamental to transacting business around the globe. With the added convenience of online transactions also comes the risk of electronic fraud. Although companies such as eBay have operated for the last 10 - 15 years, very little auction data has been collected and made publicly available or analysed, to the knowledge of the authors. Before any assertions about the amount of fraud in online auctions can be made, the underlying nature and structure of online auctions must be understood. In this paper we present definitions of a good auction from the viewpoints of the stake holders of the auction (e.g., bidder, seller, auctioneer, etc.) and then provide an analysis of auction data methodically collected from live eBay auctions. We collected data from 1005 auctions for three commonly available electronic devices. We show that the number of bids per auction is independent of the duration of the auction, and that the proportion of proxy bids is also approximately constant, for the duration of the auction. However, the final bid price achieved during the auction is shown to be related to the duration. Although these results are preliminary, we believe that they provide a significant insight into online auction behaviour.
\end{abstract}

\section{INTRODUCTION}

$\mathrm{eBay}^{1}$, the world's biggest online auction service is becoming more popular each day. The number of auctions hosted by eBay has risen from 800,000 auctions a day in 1998 [2] to more than 17 million auctions a day by mid 2008 (source: Medved ${ }^{2}$ ). However, despite the hype, recorded complaints regarding online auction fraud continue to increase in parallel with eBay's popularity. The 2007 annual report of the Internet Crime Complaint Centre (IC3) 3 stated that online auction fraud is the most reported offence accounting for $35.7 \%$ of referred crime complaints (see [11]). Then follows non-delivery of items (or misrepresented items) which accounts for another $24 \%$ of the recorded complaints (a $31.1 \%$ increase from the 2006 IC3 annual report).

In order to thwart certain types of undesirable behaviour, eBay revised its auctioning format in 2006 [4]. A seller has the option to either completely hide the bidders' IDs, mask the bidders' IDs such as $\mathrm{r}^{* *} \mathrm{t}, \mathrm{p}^{* * *} \mathrm{r}, \mathrm{s}^{* * * *} \mathrm{y}$, etc., or represent the bidders' IDs as bidder0, bidder1, bidder2, bidder3, etc. According to eBay, the policy protects buyers from receiving fake second chance offers from scammers (i.e., a bidder loses the auction but is later contacted by the seller or another seller

\footnotetext{
${ }^{1}$ http://www.ebay.com

${ }^{2}$ www.medved.net

${ }^{3}$ http://www.ic3.gov
}

who offers him/her the same item). eBay claims that the policy is a success as it prevents scammers from contacting bidders currently engaged in auctions in an effort to sell a similar item.

However, it would seem that while this policy may make it harder for the aforementioned type of dubious behaviour, it appears that it can potentially trigger more serious behaviour (such as shill bidding [8]) that is even more dangerous for buyers. Furthermore, given the fact that auction fraud has continued to increase well into the tenure of the new anonymous auction format, this casts serious doubts on the claims eBay has made regarding its success at preventing auction fraud. As yet eBay's claims have not been justified by empirical evidence. Furthermore, significant debate on eBay's forums by auction participants seems to point to growing unrest with the policy and eBay's inability to prevent auction fraud.

Although there is evidence of online auction fraud (e.g., annual report of IC3), this evidence depends almost entirely on people reporting the crime. There are two problems associated with relying on this data. The first is that people may decide not to report an attempted fraud for a variety of reasons including unwillingness to become involved, or they don't believe anything will eventuate from it. Secondly, the victim may not even be aware that fraud has taken place; the classic example of this is shill bidding, where the unsuspecting bidder is tricked into bidding more than is necessary to win the contested item. As noted previously, the modifications made by eBay may well help to deter fraudulent activity that will affect the auctioneer and the seller. However, it is not clear that hiding bidder identity will help genuine bidders detect shill bidding or other fraudulent activities.

While preliminary work has been performed by researchers into detecting and preventing online auction fraud (see [3], [6], [7], [9]), the effectiveness of these techniques typically rely on the availability of real online auction data and the ability to analyse bidding trends. Although companies such as eBay have operated for the last 10 - 15 years, very little auction data has been collected and made publicly available for the purposes of understanding the nature of online auction fraud perpetrators. Before any assertions about the amount of fraud in online auctions can be made and validated, the underlying nature and structure of online auctions must be understood. This will then create an environment for devising more accurate and effective anti fraud techniques.

In this paper we present definitions of what is considered a good auction from the viewpoint of the auction stake holders (e.g., bidder, seller, auctioneer, etc.) and then provide an 
analysis of auction data methodically collected from live eBay auctions. We collected data from 1005 auctions for three commonly available electronic devices. These auctions had durations of 1 day, 3 days, 5 days, 7 days and 10 days. During an auction a bidder can list a single bid for an item, or introduce a proxy bid that includes an initial bid (active bid) and then an agent updates the bids accordingly (using proxy bids). We show in this paper that the percentage of active bids is the same for all of the auction durations and the items sold. However, the final bid price achieved during the auction is shown to be related to the duration. Although these results are preliminary, we believe that they provide a significant insight into online auction behaviour, and therefore form the basis for further study into developing anti fraud techniques.

This paper is organised as follows: Section II briefly describes the online auction format and discusses the various types of auction fraud. Section III attempts to define what is considered to be a "good auction" from differing auction participants' perspectives. Section IV presents a preliminary analysis into online bidding trends using real online auction data collected from eBay. Section $\mathrm{V}$ provides some concluding remarks and avenues for future work.

\section{OnLINE AUCTIONS AND AUction Fraud}

\section{A. The Online Auction Format}

Online auctions have similarities to traditional offline English auctions. However, there are numerous subtle differences. The most notable difference is the use of a predetermined closing time. Bidders can submit bids up until the closing time. The highest bidder at the end of the auction is deemed to be the winner.

The next most notable difference is the employment of software bidding agents that bid on the human bidders' behalf. In eBay this is referred to as proxy bidding. The bidder enters the maximum amount $\mathrm{s} / \mathrm{he}$ is willing to pay and the bidding agent will automatically raise his/her bid incrementally up to the maximum each time s/he is outbid.

Furthermore, online auctions offer bidders the ability to retract a bid. While this is not encouraged, it is allowed in the situation where a bidder may have entered an incorrect amount. For example, s/he has entered $\$ 200.00$ instead of $\$ 20.00$.

Similarly to traditional auctions, online auctions provide the seller the ability to place a reserve on the auction. The reserve price is the minimum amount that a seller will accept for the item. If this price is not attained, then the auction is nullified.

Online auctioneers also offer differing auction formats for sellers [10]. For example, eBay's "Buy it now" format allows the seller to advertise a price that a bidder can instantly accept to win the auction. The auction will proceed as normal if no one accepts this price. That is, the highest bidder will still win.

Additionally, online auctioneers provide auctions whereby large businesses such as Disney and Dell Computers can offer goods for auction directly to customers. However, for the purpose of this paper, we are focusing on normal auctions that are of a consumer-to-consumer nature. That is, they are not
"Buy it now" style auctions, nor do they involve medium to large businesses placing items up for auction. We do however, include data from auctions where the reserve price is not met.

\section{B. Online Auction Fraud}

Trevathan and Read [8] provide a comprehensive discussion of the common types of fraudulent and undesirable behaviour in online auctions, and also describe the basic effects these have on the auction process. The major categories of online auction fraud include:

- Non-existent or Misrepresented Items - A seller either doesn't deliver an item or misrepresents it to be something other than what the bidder believed s/he was bidding for.

- Bid Shielding - A bidder puts in an extremely high bid to deter other bidders from making further bids on an item. Just before the auction's end, the bid is withdrawn and the bidder enters a new bid for the minimal amount required to win (thus taking a bargain).

- Bid Sniping - A bidder bids the minimal amount required to win in the closing seconds of an auction thereby denying other bidders time to react and keeping the price as low as possible.

- Bid Siphoning - An outsider observes an auction and directly contacts the bidders with a cheaper item, thereby avoiding auction listing fees.

- Shill Bidding - A seller introduces bogus bids into his/her own auction in an attempt to artificially inflate the auction price.

There are minimal mechanisms in place to thwart the aforementioned types of bad behaviour. The most well known is eBay's feedback system [5]. Buyers and sellers rate each other based on their dealings. However, the effectiveness of this system is unclear as nearly all people have at least a $97 \%$ rating. Also it is easy to generate fake feedback using multiple auctioning accounts

The next kind of mechanism to prevent fraud is the new bidder masking policy. It is claimed that this provides anonymity for the purposes of preventing bid siphoning. But it would appear that this policy is conducive to shill bidding. As bidders are now completely anonymous, it is much harder to determine whether a specific bidder (or group of bidders) is responsible for submitting the majority of the bids. This has the effect of obscuring bidder behaviour which means it is easy to get away with shill bidding. While the bidder masking policy benefits the Auctioneer and the seller, it is less beneficial to buyers.

\section{What IS A GOOD AUCTION?}

This section considers the auctioning process from various participants' perspectives. Here we define a "good auction" as an auction in which some aspect is optimised for a specific participant. The reason for doing this is to use these perspectives as a baseline to investigate typical online auction fraud (such as those outlined in Section II-B). However, note here that we do not provide an analysis of online auction fraud using these baselines in this paper. Furthermore, this paper 
does not seek to provide a rigorous economic analysis, but rather a common sense approach that arises from observing actual online auctions over a period of time. Furthermore, we note that it may not be possible to measure all of the identified characteristics using the data collected.

Before examining desirable auctioning characteristics, we must first define a null auction. A null auction is an auction where a listed item does not attract any bids. This is negative for the seller as s/he must relist the item thereby incurring more listing fees. It is also negative for the Auctioneer as null auctions are perceived as being unsuccessful in drawing adequate attention to its site. This can have effect of losing the auctioneer business as sellers will be less inclined to list with them in the future.

The concept of a null auction can be further divided into two categories. An auction may be unsuccessful as it has failed to attract any bids. We refer to this as a bid null auction. Alternately, an auction that has a reserve price may fail due to the reserve not being met. That is, the auction had bids, but was unsuccessful as it did not reach the minimum price asked for by the seller. We refer to this type of auction as a reserve null auction. Note that reserve null auctions will still exhibit genuine bidder behaviour and the final bid, although not recognised by the seller (due to the price reserve), is still indicative of the price the bidders in the auction wish to pay. For this reason, we include reserve null auctions in the data presented. Both types of null auction will require the seller to relist the item (i.e., the item does not sell). All other auctions result in the item being sold. We will refer to these auctions as valid auctions.

A buyer considers an auction to be good or successful when:

1) The auction is valid;

2) There are few or no competing bids;

3) There are few or no competing bidders;

4) There is no reserve price;

5) There is complete/reasonable information about the item being bid for;

6) $S$ /he obtains an item for the lowest price possible;

7) There are no hidden fees (e.g., postage, handling, insurance);

8) The quality of the item on auction (either used, or new) substantially meets the buyer's expectations; and

9) The item is delivered promptly.

Only the first four points can be determined from the raw auction data. The remaining information needs to be determined using feedback from the buyer and as such can only be determined by feedback mechanisms like the one used by eBay.

A seller considers an auction to be good or successful when:

1) The auction is valid;

2) There are numerous competing bids;

3) There are numerous competing bidders;

4) $S /$ he receives the highest price possible for an item;

5) The buyer is satisfied with the transaction; and

6) There is prompt payment by the buyer.
Only the first three points can be determined from the raw auction data. Similarly the remaining information must be gauged from eBay's feedback system.

An Auctioneer considers an auction to be good or successful when:

1) The auction is valid;

2) There is prompt payment by the seller;

3) There is a perception by the non-participating public of a well-run auctioning process;

4) The buyer and seller use any optional tools provided by the auctioneer; and

5) The buyer and seller are satisfied with the process and the auction.

The Government considers the auctioning process as being successful when:

1) The auctioning process satisfies the needs of the community (buyers, sellers, non-participating public);

2) There is a clear and transparent process that satisfies the law and business ethics;

3) The auction offers a fair trading process without bias to bidder and seller; and

4) The auction's structure minimises the risk of illegal (and fraudulent) activity.

Unethical/illegal participants consider an auction to be good when:

1) The structure of the auction is conducive to fraudulent behaviour. (In particular any of the types of behaviour outline in Section II-B.)

\section{AnAlysing BidDing TREnds}

This section presents an analysis of real auction data collected from eBay.

To collect valid and quality auction data we need to focus on items where large amounts of data are available. This excludes specialist auctions for rare items which are likely to have limited data (i.e., few auctions and a small number of bidders). For this reason we collected data from items that were newly released in the market and were considered as "trendy", or "must have" items. This ensured a high volume of auctions and as a consequence a high number of bidders and sellers.

We collected data from three commonly available, desirable electronic items. These were the Nokia N95 $8 G B$ mobile phone, Sony Playstation 3, and Apple iPhone. (Refer to Balingit et al. [1] for exact details regarding the data collection process.)

We started collecting the auction data in 2008 when these items were new and freshly released into the market. We collected data from 335 auctions for each of these items respectively - 1005 auctions in total. These auctions had durations of 1 day, 3 days, 5 days, 7 days and 10 days. A total of 28182 bids where collected across all three items. There were 13705 bids for the Nokia N95 8GB, 12904 bids for the Sony Playstation 3 and 12573 bids for the Apple iPhone.

Figure 1 gives the percentages of the auctions that are of 1 day, 3 day, 5 day, 7 day and 10 day duration for each item 


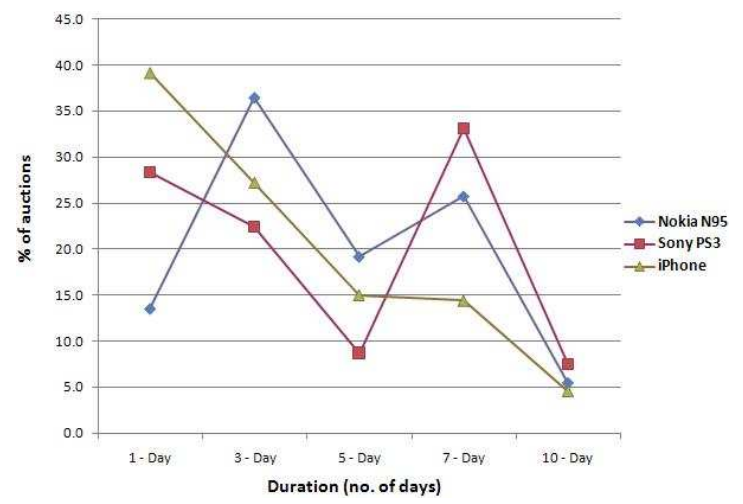

Fig. 1. The percentage of auctions of 1 day, 3 day, 5 day, 7 day and 10 day durations.

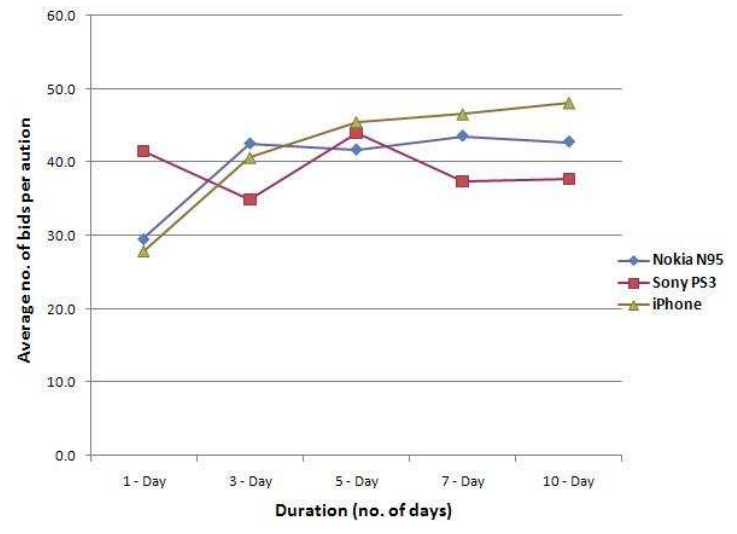

Fig. 2. The average number of bids per auction for each item.

(the percentages are taken out of 335). We note from Figure 1 that there is a wide variation in the number of days that sellers prefer for their auctions. There is evidence to suggest that there is preference amongst sellers for 3 day and 7 day auctions, with 5 day and 10 day auctions the least preferred. We note here that the total number of 10 day auctions for each item is relatively small, ranging from 15 to 25 , and that less reliance can be put on any result for these auctions, due to the small size of this data set.

Given the uneven preference for the duration of these auctions, we need to normalise the number of bids in each category, so that we can compare results for auctions of different durations. There are two possible normalisation schemes that we will consider for this paper. The first one is the average number of bids per auction (refer to Figure 2), and second one is the average number of bids per auction per day (refer to Figure 3).

An examination of Figure 2 shows that the number of bids per auction is approximately the same independent of the duration of the auction. There is some evidence to suggest that there are slightly less bids in the one day auctions and a very slight increase in the number of bids as the duration increases. However, normalising just by the number of auctions appears to give reasonable standardisation of the data.

An examination of Figure 3 now can shed light on whether or not the number of bids increases with the duration. We see that as the number of days increases, the average number of bids per auction per day decreases sharply. The average numbers of bids per auction per day for each of the three items converge to approximately the same value for all durations except for one day auctions. This verifies the result for Figure 2. That is, the duration of the auction has little bearing on the number of bids for 3 day, 5 day, 7 day and 10 day auctions. The number of bids in an auction is slightly lower for 1 day auctions and if necessary we could break the auctions into two categories: auctions of 1 day duration and auctions of greater than 1 day duration. However, we note here that the difference in these two categories is relatively slight and we now make our first claim - "The number of bids per auction is independent of the number of days in an auction". A typical auction will have between 35 and 45 bids.

Next, we want to consider the nature of the bids in an auction and investigate bidder behaviour accordingly. We classify the two types of bid that are used by a bidder when participating in an auction - an active bid and a proxy bid. A bid that is manually entered by a bidder without using an 

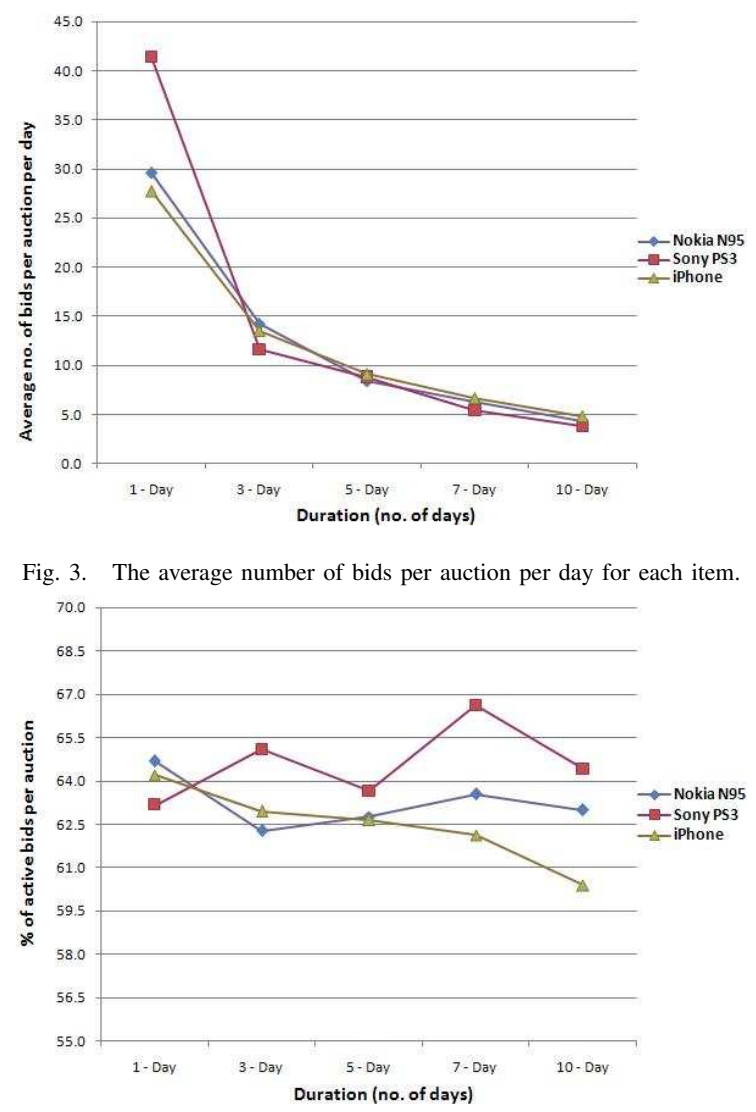

Fig. 4. The percentage of active bids for each item.

automatic bidding agent is called an active bid. A bid made on a bidder's behalf by an automatic bidding system is called a proxy bid.

Normalising the auction data using the average number of bids in an auction, we can break the bids up into active and proxy bids.

Given the two ways to submit bids in an auction, we normalize the percentage of active bids in auctions for 1 day, 3 day, 5 day, 7 day and 10 day durations. Figure 4 shows the percentage of active bids submitted in auctions for 1 day, 3 day, 5 day, 7 day and 10 day durations. An examination of Figure 4 suggests that approximately $60 \%$ to $67 \%$ of the bids in an auction are active bids independent of the duration of the auction. That is, the percentage of active bids remains constant across 1 day, 3 day, 5 day, 7 day and 10 day auctions. There is a slight percentage decrease in the Apple iPhone as the duration increases. However, overall we assert our second major conjecture - "60-67\% of the bids in an auction are active bids".

Note that we can calculate this percentage from the raw data for the auctions, or from the normalised data (using either normalisation - the results are identical).

We next consider the final bid price in each of the 1 day,
3 day, 5 day, 7 day and 10 day durations. Figure 5 shows the average final bid price per auction in \$USD. An examination of Figure 5 reveals that the final price is approximately the same for the 3, 5 and 7 day auctions for the Apple iPhone, and the 7 and 10 day auctions for the Nokia N95 8GB and Sony Playstation 3. Both the Apple iPhone and the Nokia N95 8GB final bids increase as the duration increases with the most significant jump from the 1 day to the 3 day auctions. Paradoxically the final bid achieved for the Apple iPhone in the 7 day auction is lower than all the other auctions, save the 1 day auctions. We note here that the 1 day auctions return the lowest average bid price in all of the categories except for one (the Sony PS3 3 day average final bid, and even in this case the 1 day average is only slightly higher).

We conjecture that "the duration of the auction does have some effect on the final price bid". In particular 5 or 10 day auctions tend to have a higher final bid price than 1 or 3 day auctions. The average final bids for the 1 day auctions are almost always the lowest, the only exception is for the Sony Playstation 3 where the average 1 day price is higher than the 3 day price, but is still lower than the other final bid prices. We note here that the average final bids for the 3,5 or 10 day auctions are all higher. 


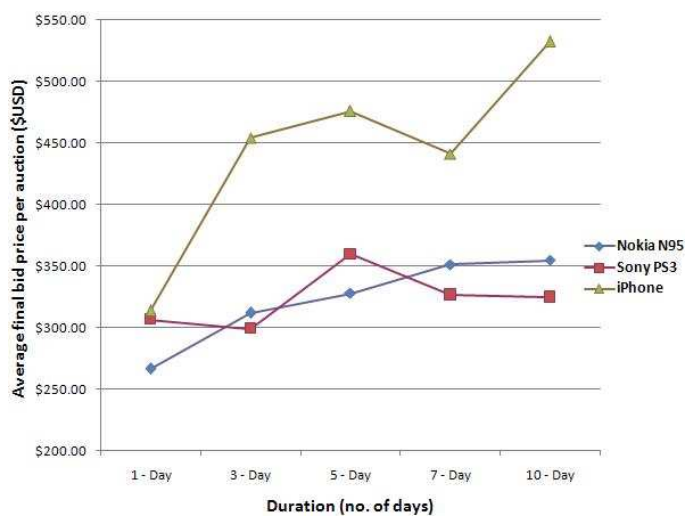

Fig. 5. The average final price for 1 day, 3 day, 5 day, 7 day and 10 day for each item.

\section{CONCLusions}

The conventional wisdom with regard to auctions is that the bidder has a fixed upper limit on spending and should then cease bidding. Under this hypothesis one would expect to see a wide distribution of bids, varying with the number of days in the auction and the item being auctioned. However, we are not observing this behaviour here in the auctions analysed, as the number of bids per auction is independent of the length of the auction, the item being auctions and the final bid price. This is at variance with the conventional idea of each bidder having a fixed final bid. However, before we can make any conjectures in this regard we have to examine the bidding data for each auction more closely. This will be focus of future work.

Following the same principle we would expect to see varying amounts of proxy bidding across the different types of auctions. We note here that the amount of active bidding is a relatively narrow band (60-67\%) and appears to be independent of the duration of the auction or the item being sold. Once again before we can draw any strong conclusions regarding the underlying behaviour of the bidders, we will need to analyse the individual auction data in more detail. This is also an area for future research.

We note that the final bid price achieved in the auctions does depend to some extent on the duration of the auction. We draw attention here to the fact that the one day auctions performed the poorest almost without exception. We also note that the number of bids and the proxy bids for the 1 day auctions had the largest variation of all of the auction durations. We believe that the one day duration does not allow the auction to establish and settle in to a "steady state" - the auction is still in "start up mode". We also note that 3 and 7 day auctions appear to be the most popular amongst sellers wishing to sell their goods. Our research based on the data presented in this paper suggests that 5 day auctions, which were relatively unpopular, perform better on average. There is a question mark over the results for the 10 day auctions. These are the least favoured of the auction durations used by sellers and we have only been able to collect limited data on them. In fact for the three items mentioned, we only had data for 15 to 25 auctions.
The behaviour of the final bid price in the longer auctions is also interesting particularly when we examine the Apple iPhone. For the other two auction items the price remains relatively constant over the 5, 7 and 10 day auctions (with a small increase or decrease), conversely there was a sharp increase in the final bid price for the Apple iPhone. Although we cannot make any conjectures at this stage, this data needs to be examined to see if there is any evidence of fraudulent behaviour (i.e., shilling) or if this is just an aberration due to the comparatively small size of the data set used.

\section{REFERENCES}

[1] R. Balingit, J. Trevathan, Y. Lee and W. Read, "A Software Tool for Collecting Data from Online Auctions", In the Proceedings of the International Conference on Information Technology - New Generations, (to appear), 2009.

[2] M. Bredel, "eBay's Success and Popularity", Online, http://ezinearticles.com/?eBay-Success-and-Popularity\&id=648075, 26 July 2008.

[3] Y. Cheng and H. Xu, "A Formal Approach to Detecting Shilling Behaviours in Concurrent Online Auctions", in Proceedings of the $8^{\text {th }}$ International Conference on Enterprise Information Systems, 2006.

[4] C. Dawson, "eBay Oz to mask ids on all auctions", Online, http://www.tamebay.com/2008/ebay-to-mask-all-buyer-ids-onauctions.html, 18 August 2008.

[5] C. Dellarocas. "The digitization of word-of-mouth: Promise and challenges of online feedback mechanisms". Management Science, 49(10):14071424, Oct. 2003. auctions. Press release, Nov. 2004.

[6] S. Rubin, M. Christodorescu, V. Ganapathy, J. Giffin, L. Kouger and H. Wang, "An Auctioning Reputation System Based on Anomaly Detection", in the Proceedings of the $12^{\text {th }}$ ACM Conference on Computer and Communications Security (CCS), pages 270-279, Alexandria Virginia, 2005.

[7] H. Shah, N. Joshi and P. Wurman , "Mining for Bidding Strategies on eBay", in SIGKDD'2002 Workshop on Web Mining for Usage Patterns and User Profiles, 2002.

[8] J. Trevathan and W. Read, "Fraudulent and Undesirable Behaviour in Online Auctions", in SECRYPT'06, pp. 340-347, 2006.

[9] J. Trevathan and W. Read, "Detecting Shill Bidding in Online English Auctions", Handbook of Research on Social and Organizational Liabilities in Information Security, IGI Press, Chapter 27, Pages 446-470, 2008.

[10] eBay, "Guide to Buying Formats", Online, http://pages.ebay.com.au/help/buy/formats-ov.html, 04 August 2008.

[11] The National White Collar Crime Center, Bureau of Justice Assistance, Federal Bureau of Investigation, "2007 Internet Crime Report - Internet Crime Complaint Center", Online, http//www.ic3.gov/media/annualreport/2007-IC3Report.pdf, 28 July 2008. 